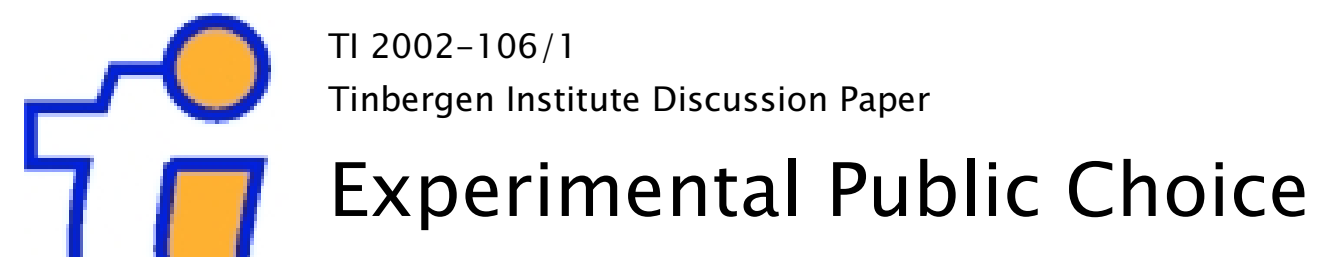

Arthur J.H.C. Schram

CREED, Faculty of Economics and Econometrics, University of Amsterdam, and Tinbergen Institute. 
Tinbergen Institute

The Tinbergen Institute is the institute for economic research of the Erasmus Universiteit Rotterdam, Universiteit van Amsterdam and

Vrije Universiteit Amsterdam.

Tinbergen I nstitute Amsterdam

Keizersgracht 482

1017 EG Amsterdam

The Netherlands

Tel.: +31.(0)20.5513500

Fax: $\quad+31 .(0) 20.5513555$

Tinbergen Institute Rotterdam

Burg. Oudlaan 50

3062 PA Rotterdam

The Netherlands

Tel.: $\quad+31 .(0) 10.4088900$

Fax: $\quad+31 .(0) 10.4089031$

Most TI discussion papers can be downloaded at

http://www.tinbergen.nl 


\title{
Experimental Public Choice
}

\author{
by \\ Arthur J.H.C. Schram \\ (O) (C) $R E D$ \\ Department of Economics and Econometrics \\ Roetersstraat 11 \\ 1018 WB Amsterdam \\ the Netherlands \\ ArthurS@fee.uva.nl
}

The author would like to thank Jens Großer and Theo Offerman for useful comments. 


\section{Introduction}

A few decades ago, most economists believed that their discipline was non-experimental. Economic phenomena should be studied theoretically or empirically. The ideal paper was one where rigorous theory was tested using advanced econometric methods. The fact that the empirics were usually based on (often incomplete) field data only remotely related to the problem at hand was no problem: this is why we had econometrics.

Over the past decades, Economics has rapidly become an experimental science, however. It has become obvious to many that laboratory experiments provide the means to control conditions in a way that allows for a systematic test of economic theories. Contrary to econometric testing, laboratory testing allows one to systematically test essential elements of a theory. In addition, experiments can be used to explore potential paths of new research, in situations where no theory exists or where existing theory is shown to be inadequate. Finally, experiments have the advantage that they can be replicated, allowing for a systematic analysis of the robustness of the findings.

The use of laboratory experiments in public choice research has also increased rapidly in the last thirty years or so. At meetings of the various public choice societies, it has become very common to encounter experimental papers. This is no coincidence but has been actively solicited by the societies themselves. For example, it is a well-established tradition that the North American Public Choice Society organizes its yearly spring conference together with the Economic Science Association (the international society of experimental economists). The bylaws of the European Public Choice Society even explicitly state that "The Society's interest is in theoretical rigor, empirical and experimental testing, and real world applications".

The increased use of experiments in public choice is definitely an enrichment to this literature. Much of the literature on non-market decision-making is based on theoretical assumptions about individual behavior (see Schram, 2000) or on field data from elections or surveys that are not particularly tailored to answer the questions raised by the theory. In both cases, experiments provide a method that is complementary to the existing methods. Together with theory and empirics based on field data, experiments allow us to understand public choice phenomena in more depth.

Two types of experimental studies can be important for public choice. One group is concerned with individual behavior and motivations. Its conclusions with respect to individuals' motivations and preferences (Schram, 2000), or the role of emotions and bounded rationality (Bosman, 2001; Bosman and van Winden, 2001), for example, can have important consequences for the assumptions made in many public choice theories. This type of studies 
is not discussed in detail in this essay, however. A brief evaluation of their importance is given in the concluding section. A detailed discussion of their relevance to public choice can be found in Schram, 2000. Instead, this essay focuses on a second group of studies: those where experiments are used to analyze a number of traditional public choice topics. ${ }^{1}$

This essay is organized as follows. The next section briefly describes the experimental methodology. This is followed by four sections on experiments in public choice: public goods (section III), voter turnout and participation games (section IV), rent seeking and lobbying (section V), and spatial voting (section VI). A concluding discussion is presented in section VII.

\section{Experimental Economics}

In a laboratory experiment, behavior is studied in a controlled environment. Participants (in most cases university students) are invited to a computer laboratory, where they are asked to make decisions in a framework designed by the experimenter. Decisions are 'real', e.g., in the sense that they have monetary consequences for the subjects. At the end of the experiment, they are paid in cash an amount that depends on their own decisions and (in many cases) on the decisions of other participants. An excellent description of what an experiment in economics entails and how one can set up an experiment is provided in Davis and Holt (1993).

Traditionally (e.g., Smith, 1994), one distinguishes the environment, institutions and behavior in an experiment. The environment refers to the structural characteristics of an economic problem, such as the number of agents, the information structure, preferences, endowments, cost structure, etc. According to Davis and Holt (1993), economists traditionally viewed economic problems almost exclusively in terms of these characteristics. Institutions refer to the rules governing the interaction of economic agents, such as the market or auction rules, or the government decision-making procedures. For a long time, it was argued that it is possible to control the environment and institutions in an experiment and to study behavior. By varying institutions, for example, one could investigate how they affect behavior.

Two caveats can be made with respect to this traditional distinction, however. First of all, one can argue that many non-experimental economists have considered the importance of institutions as well. The boom in institutional economics and game theory has highlighted the important effects they may have on behavior. Second, it is not obvious that one can control

\footnotetext{
${ }^{1}$ A third group of studies observed is that of 'political engineering': experiments are used to help design
} 
the environment completely. Especially preferences might be difficult to control in a laboratory. Though one tries to induce preferences by offering a payoff scheme, one cannot control individual preferences for other things than the own private earnings. Nevertheless, it is obvious that the laboratory allows for a much higher level of control than was possible before.

Experimental results can therefore carry much weight. The control in a laboratory allows one to address very specific research questions. For example, if we are interested in studying committee voting on two proposals under two different voting rules (see section VI), there is no better setting to study this than in an experiment where the only treatment variable is the voting rule. Keeping all other aspects of the problem constant (e.g., number of members, payoff to each member if either proposal is accepted, etc.) the environment is stripped of all the confounding elements we typically observe in the outside world. What remains is exactly what we want to study: the effect of the voting rule. If we combine an analysis along these lines with a theoretical analysis and an empirical analysis using field data, this will likely lead to a much more complete understanding of the problem at hand than we would be able to achieve without the laboratory data.

Of course there are also disadvantages related to using the experimental method. Many of theses are discussed in the standard texts in this field (Davis and Holt, 1993 or Kagel and Roth, 1995). Plott (1982) systematically discusses questions raised by economists about the validity of laboratory experiments. Here, we briefly discuss the issue of external validity, i.e., is the evidence obtained in a laboratory relevant for the 'outside world'?

Naturally, the external validity of an experiment depends on the experimental design. There is no reason why the external validity of all laboratory experiments per se should be doubted, however. Subjects participating in an experiment are real people. They are facing real monetary incentives that (in a carefully designed experiment) are salient. Hence, if we observe certain behavior in an experiment it is economic behavior. ${ }^{2}$ Nevertheless, every experimental design should be critically assessed with respect to the structure and its relationship with the problem being studied. In general, a thorough theoretical analysis of the problem at hand is useful in this assessment.

political systems. See Riedl and van Winden (2001) for an example.

${ }^{2}$ It is, of course, possible that the behavior observed is specific to the particular kind of subject in the experiment (usually students). This is a problem related to common experimental procedures as opposed to the experimental method as such, however. 


\section{Public Goods Experiments}

Public goods experiments usually study voluntary, individual, contributions to a public good. Given the role that government plays in providing public goods and the possibility that government provision crowds out individual contributions, this is of obvious importance in public choice. It is therefore no surprise that one of the first major papers on this topic was published in the journal Public Choice (Isaac et al., 1984). Since then, studies on voluntary contributions to public goods have been a major part of the experimental literature.

The typical setup of a public goods experiment is as follows. Subjects are allocated into groups of size $\mathrm{N}$ (typically, $\mathrm{N}=4$ or 5). Each is given an endowment of 'tokens'. These must each be invested in either a 'private account' or a 'public account'. Each token in the private account gives a payoff A to the subject alone. Each token in the public account gives a payoff B to every participant in the group. Hence, an investment in the public account is a voluntary contribution to a pure public good. The interesting cases are where $\mathrm{B}<\mathrm{A}<\mathrm{NB}$, because this implies that contributing nothing to the public good is a dominant strategy, whereas contributing all tokens is efficient. The relative payoff to the two accounts, A/B, gives the marginal rate of substitution (hereafter, mrs) between private and public account. ${ }^{3}$

Ledyard (1995) presents a first extensive survey of experiments of this type. Some important regularities listed in his survey are:

i) contributions to the public good start at a relatively high level (typically $40-60 \%$ of the endowments);

ii) with repetition, these contributions decrease to $0-30 \%$; very often they do not decrease to zero, however (Isaac et al, 1994);

iii) the contribution levels are a decreasing function of the mrs.

To these regularities, one can add:

iv) contributions increase with group size (Isaac et al., 1994);

v) many subjects split their tokens across the two accounts, i.e., they don't contribute everything to one of the two accounts (Palfrey and Prisbrey, 1997; Brandts and Schram, 2001);

vi) there is considerable subject heterogeneity: systematic differences across subjects 
exist; some consistently contribute, some never do; others switch from contributing to not contributing (Palfrey and Prisbrey, 1997; Brandts and Schram, 2001);

vii) if group composition is held constant across periods, contributions get more concentrated in groups as the experiment moves on (Brandts and Schram, 2001).

The type of public goods experiments described is by far the type most often studied. The linear production function for public goods is easy for subjects to understand and provides an interesting tradeoff between private earnings and group welfare. ${ }^{4}$ Over the last few years many extensions to the setup have been studied, often in an attempt to study other regarding preferences or reciprocity (see Schram, 2000, or Fehr and Gächter, 2000a, for an overview). These extensions include the study of situations where there is no efficiency gain to be made from cooperation (Palfrey and Prisbrey, 1997, Brandts and Schram, 2001); cross-cultural comparisons (Cason et al., 2002, Brandts et al., 2002); framing (Andreoni., 1995a, and Sonnemans et al., 1998); and the effect of allowing costly punishment of free riders (Fehr and Gächter, 2000b).

The bottom line in this whole body of literature is that subjects in public goods experiments contribute voluntarily to the public goods, to a much larger extent than the selfish individually rational prediction of free riding would have them do. In addition, contributions cannot simply be attributed to erratic behavior of the subjects (Andreoni, 1995b, Brandts et al., 2002). On the other hand, contributions tend to be lower than the efficient level, many subjects do free ride and contributions decrease with repetition. There is an ongoing discussion about what motivates subjects to behave in this way.

From a public choice point of view, the relationship between group size and free riding is of interest. Mancur Olsen's idea that free riding will increase with group size is not supported by the experimental data. On the contrary, contributions increase with group size (see regularity iv, above). ${ }^{5}$ Isaac et al. (1994) show that it is not group size per se that matters, but the interaction between group size and mrs. Keeping the mrs constant, the 'pure' group size effect is positive (if the mrs is large enough). At this stage, it is difficult to understand this apparent anomaly. One possibility is that it is related to the gains from cooperation (Brandts and

\footnotetext{
${ }^{3} \mathrm{It}$ is also quite common to refer to $\mathrm{B} / \mathrm{A}$ (i.e., $1 / \mathrm{mrs}$ ) as the marginal per capita return (mpcr); see Isaac et al. 1984.

${ }^{4}$ Another widely studied case is where the production technology uses a threshold: a minimum amount of contributions needs to be collected for the public good to be produced. These 'step-level public goods' are extensively studied in Offerman et al. (1996). A meta-analysis is given by Croson and Marks (2000).

${ }^{5}$ On the other hand, Offerman et al. (1996) show that voluntary contributions decrease with group size in a step-level public goods game.
} 
Schram, 2001). For any given mrs, a specific number $\mathrm{k}$ of contributors is needed to make them better off (as a subgroup) than if none of them would contribute. The larger the group, the more likely it is that there will be k contributors. From an individual's point of view, in a large group it is less likely that he will be a 'sucker', for whom the cooperative gain is smaller than the individual contribution to the public good.

\section{Voter turnout as a participation game}

The paradox of voter turnout has been the subject of academic debate for decades (for an early survey, see Schram, 1991). The debate probably started with Downs' (1957) formulation of the problem. He notes that, due to the low probability of being decisive, the expected benefits from voting in a large-scale election are generally outweighed by the cost of the act. Nevertheless a very large number of voters actually turns out to vote in general elections. Many theoretical and empirical papers have been published trying to explain the paradox, but only few rational choice models have been developed that show that turning out to vote might sometimes be rational in an instrumental sense (see Ledyard 1984, or Schram 1991, and the references given there).

Palfrey and Rosenthal (1983) model the turnout problem as a participation game and study it game-theoretically. In this game, there are two or more teams. Everyone has to make a private decision that is beneficial to every member in one's own team and harmful to members of other teams. The decision is whether or not to 'participate' in an action, where participation is costly. Palfrey and Rosenthal show that in many cases, Nash-equilibria with positive levels of participation exist. Note that there are two types of conflicts in a participation game. Within the group, there is an incentive to free-ride on the costly participation of other group members. Between groups, there is an incentive to compete and out-vote the other group. Note the difference with the incentives in the public goods games of the previous section, were only the free-riding incentive exists.

It is difficult to study voter turnout using field data. ${ }^{6}$ Participation games provide a structure to study this decision experimentally, however. This was first done by Bornstein (1992) and Schram and Sonnemans (1996a,b). Here, we shall describe the experiment used in the latter two papers. In the experiments, subjects are split in two groups of 6 individuals. Each subject had to decide whether or not to buy a token at a given price. The number of tokens bought in

\footnotetext{
${ }^{6}$ Güth and Weck-Hanneman (1997) and Blais and Young (1999) use field experiments to study the paradox of voter turnout. In both cases, the turnout decision of a group of students in a real election is monitored. Güth and Weck-Hannemann study the value of a vote by offering a payment in return for
} 
each group determines the payoffs. There were two payoff schedules, representing a winnertakes-all election $(W I N)$ and proportional representation $(P R)$. In WIN, each member of the group that bought the most tokens (won the elections) received a fixed sum and the payoff for the other group was zero (with ties broken randomly). In $P R$ the payoff to any group-member was proportional to the relative turnout of the groups. In addition to these experiments, two WIN sessions were run with groups of 14 subjects and two where one group consisted of 8 and the other of 6 participants. The results obtained show:

i) Nash equilibrium is a poor predictor of turnout;

ii) participation is higher in winner-takes-all than in proportional representation; this is in line with the comparative statics of the pure strategy equilibria;

iii) participation is higher with repetition in fixed groups;

iv) participation increases substantially after five minutes of free communication;

v) there is no significant effect of group size on relative turnout;

vi) when groups size is unequal, relative turnout is higher in the smaller group.

To date, there have not been many other published experimental studies on participation games. A number of recent working papers are dedicated to these games, however. These include Cason en Mui (2001) on the role of participation costs and uncertainty with respect to the benefits of voting. They find that increasing costs cause decreasing participation rates. Uncertainty has mixed effects, depending on which subjects are facing it.

With different co-authors, Großer studies three extensions to the participation games: (1) the introduction of group size uncertainty (Großer and Kugler, 2002); (2) the endogenization of policy (and group) formation (Großer, Elberfeld and Giertz, 2002); and (3) the introduction of information about the turnout decision of some other voter (Großer and Schram, 2002). The results in these papers include:

vii) uncertainty about group size decreases turnout;

viii) a mix of allied and floating voters in a group yields higher turnout rates than a situation without allied voters;

ix) endogenous political ties between voters and candidates are observed, i.e., over a series of elections, candidates design policies for specific groups of voters who reward them with their votes;

x) higher turnout rates are observed when subjects are informed about the decision of other participants.

abstention. Blais and Young study the effect of being exposed to a presentation about the turnout 
The bottom line in the research on participation games is that (as in elections) traditional theory is a bad predictor of turnout. Participants often do react to a change of incentives (e.g., an increase in the costs of voting) in a predictable way, however. Moreover, the results of the recent experiments on group size uncertainty and information about other voters show how experimentation might be useful in a further analysis of the turnout paradox. Another interesting development is that some of the results observed in participation games can be explained in a quantal response framework McKelvey and Palfrey (1995). Goeree and Holt (2000) show that the results reported in Schram and Sonnemans (1996a,b) are consistent with a quantal response equilibrium.

\section{Rent-seeking and Lobbying}

Van Winden (1999, 2002) provides detailed surveys of the experimental literature on lobbying. He distinguishes three types of studies that are relevant in this respect: experiments on common agency problems, signaling models and rent seeking. We will briefly discuss the first two categories (see van Winden's surveys for more details) and elaborate a bit on the rent seeking experiments.

Common agency experiments (see Kirchsteiger and Prat, 2000) study the effect of campaign contributions in exchange for favorable policies. Lobbyists compete in offering a politician a 'contribution schedule' which depicts the (possible) campaign contribution as a function of potential policies. The politician chooses a policy and collects the contribution. One interesting experimental result is that lobbyists tend to focus on the most preferred result and do not offer significant contributions for less preferred alternatives.

In signaling games, the focus is on the strategic transmission of (relevant) information from a lobbyist to a politician. This (credibly) assumes that the lobbyist may have information that is relevant to the politician, when making his decision. Of course, there may be an incentive for the lobbyist to transmit untruthful information. The experiments of Potters and van Winden (1992) study this environment. Though their results cast doubt on the predictive power of the theoretical literature in this field, they do find that mutual beneficial (costly) transmission of information takes place from the lobbyist to the politician.

In the experimental rent seeking literature the role of the policy maker is replaced by some commonly known mechanism. The focus is on the competition between lobbyists. They

paradox. 
typically compete for a 'prize' (rent) by placing bids. The mechanisms used are typically that the highest bid wins the prize or that the probability of winning the prize is proportional to the (relative) bid. An important characteristic of this setup is that all bids are irreversible (like in an all-pay auction). This yields possible inefficiencies (overdissipation) in the lobbying process, because the sum of the bids may be higher than the value of the prize.

The main experimental studies on rent-seeking are Millner and Pratt, 1989, Davis and Reilly (1998), Potters et al. (1998), and Weimann et al. (2000). Here, we will describe the experiments in Potters et al. The mechanism used in this study to determine a winner is part of the experimental design, which distinguishes perfectly and imperfectly discriminating contests. This distinction allows the authors to compare a situation where the equilibrium strategies yield positive probabilities of overdissipation (i.e., inefficiency), with one where the probability of overdissipation is zero. In other words, the equilibrium in one experimental treatment attributes a positive probability to the event that the sum of the bids is higher than the prize, whereas another attributes zero probability to this event. The main results are:

i) the (Nash) equilibrium predictions are not supported;

ii) overdissipation is more likely when theory predicts that it will be. In other words, the point predictions derived from game theory are rejected but the predicted comparative statics are supported;

iii) subjects 'learn' to play more according to theory as they gain more experience through repetition over rounds.

The bottom line in this line of research is that only limited support for the theoretical literature on lobbying is found. This may be due to the fact that some subjects do play in line with theory, whereas others do not (Potters et al. 1998), yielding an aggregate outcome that does not provide support.

\section{Spatial Voting Experiments}

Two types of voting experiments can be observed in the literature, both starting in the late seventies and early eighties at the California Institute of Technology. Both are basically experiments on spatial voting models, one focussing on committee voting, and the other on the median voter model. ${ }^{7}$ An early survey of these experiments is presented in McKelvey and

\footnotetext{
${ }^{7}$ A limited number of other topics related to voting have been studied experimentally. These include vote trading (McKelvey and Ordeshook, 1980), voting on jury decisions (McKelvey and Palfrey,
} 
Ordeshook (1990). Because many of these studies were undertaken more than a decade ago, this survey still covers many of the important experiments in this field. A more recent survey is included in van Winden and Bosman (1996).

In the committee voting experiments, the typical setup is one, where a committee of $n$ members has to choose a point $(\mathrm{x}, \mathrm{y})$ on some two dimensional issue space. Each committee member is assigned a personal ideal point in this space and the individual payoffs are a (declining) function of the distance between this ideal point and the point chosen by the committee. A commonly known decision-making institution determines how a committee decision is determined. These institutions describe, e.g., the agenda setting, the communication and the majority rule used. Examples of this type of experiment include Berl et al. (1976), Fiorina and Plott (1978), Hoffman and Plott (1983), and Eavey and Miller (1984), who argue that this model can be considered to be a test of the Niskanen (1971) model of bureaucracy. The conclusions include:

i) if decisions are made by simple majority rule and a Condorcet winner exists, the committee decision is close to that outcome;

ii) if decisions are made by simple majority rule and no Condorcet winner exists, stable outcomes are often observed, though as yet no theoretical predictions for these outcomes are known;

iii) communication does not have a large effect on the outcome;

iv) the Niskanen model does not find support, in the sense that an agenda setter (bureaucrat) does not manage to make his ideal point the committee decision.

The median voter experiments study the interaction between political candidates and voters. The latter are given an ideal point in a one- or two dimensional policy space. Once again, their payoffs are a declining function of the distance between the chosen point and the ideal point. Candidates choose a position in the policy space, hoping to attract voters. If elected, their position is chosen and determines the voters' payoffs. Candidates' payoffs are positively related to the number of votes they receive (e.g., the winner receives a fixed amount and the loser receives nothing). Examples of this type of experiments include Collier et al. (1987), Williams (1991), McKelvey and Ordeshook (1993), and Olson and Morton (1994). The conclusions include:

1998), voting to prevent public bads (Sutter, 1999), and the aggregation of information through 
i) with complete information on ideal points and payoffs, the median voter model finds support;

ii) even with incomplete information, there is convergence to the median, when it exists;

iii) costly information on candidates' positions does not affect the rate of convergence to the median.

The bottom line of both types of voting experiments is that quite some support for theoretical predictions (Condorcet winner, median voter) is observed. Moreover, stable outcomes when no Condorcet winner exists and convergence to the median voter even in case of incomplete information indicate that the voting mechanism can lead to even more robust results than predicted by theory.

\section{Concluding Discussion}

As mentioned in the introduction, there is a large body of experimental literature that is not directly related to public choice topics, but still very relevant for the analysis of these topics. This is the literature on individual motivations and (bounded) rationality. Most of public choice theory is based on the homo economicus, who pursues his selfish preferences in a perfectly rational way.

Both of these elements have been questioned, based on experimental results (see Schram, 2000, for an overview). Many authors argue that preferences are only selfish in certain circumstances. Instead, it is argued that other regarding preferences such as altruism or fairness can be widely observed for many subjects. This observation has led to theoretical models incorporating these preferences (e.g., Fehr and Schmidt, 1999, Bolton and Ockenfels, 2000). By now, there is enough material to try to incorporate other regarding preferences in some of the traditional public choice theory.

The assumption of perfect rationality also needs to be adjusted. It is becoming increasingly clear that emotions (Bosman, 2001) and limits to rationality (Camerer, 1998) can have major impacts on behavior. In this case it is less clear how existing models could be adapted to accommodate these results, however. As yet, there is no model of bounded rationality that seems to be applicable. On the other hand, these results do create space for theories based on 'reasonable' behavioral assumptions other than perfect rationality.

elections (Wit, 1997). 
The examples given in this essay show that a variety of typical public choice topics has been studied in a laboratory environment. In some cases, this has given support to existing theories and ideas (e.g., the median voter model). In others (e.g., rents seeking), it raises doubts about the validity of the theory in its present form. In yet other cases (e.g., the turnout paradox), the experimental results can give hints as to ways to develop the theory further. In this way, experimental studies have proven to be a welcome addition to the public choice literature.

\section{References}

Andreoni, J. (1995a): "Warm-glow versus cold-prickle: the effects of positive and negative framing on cooperation in experiments", Quarterly Journal of Economics, 110, 1-22.

Andreoni, J. (1995b): “Cooperation in public-goods experiments: kindness or confusion?", American Economic Review, 892, 891-904.

Berl, J., R. McKelvey, P. Ordeshook, and M. Winer (1976): "An experimental test of the core in a simple n-person cooperative non-side payment game", Journal of Conflict Resolution, 20, 453-479.

Blais A. and R. Young (1999): "Why do people vote? An experiment in rationality", Public Choice, 99, 39-55.

Bolton, G. and A. Ockenfels (2000): "ERC: A theory of equity, reciprocity and competition", American Economic Review, 90, 166-193.

Bosman R. (2001): "Emotions and Economic Behavior", PhD-thesis, University of Amsterdam.

Bosman, R., and F. van Winden (2001): "Emotional hazard in a power-to-take experiment", Economic Journal, 112, 147-169.

Bornstein, G. (1992): "The free-rider problem in intergroup conflicts over step-level and continuous public goods"; Journal of Personality and Social Psychology 62, 597-606.

Brandts, J. and A. Schram (2001): "Cooperation and noise in public goods experiments: applying the contribution function approach", Journal of Public Economics, 79, 399-427. 
J. Brandts, T. Saijo, and A.J.H.C. Schram (2002): "A four country comparison of spite and cooperation in public goods games", mimeo, University of Amsterdam.

Camerer, C. (1998): "Bounded rationality in individual decision making", Experimental Economics, 1, 163-183.

Cason, T., T. Saijo, and T. Yamato (2002): "Voluntary participation and spite in public good provision experiments: An international comparison", forthcoming in Experimental Economics.

Cason, T. and V. Mui (2001): "Uncertainty and resistance to reform in laboratory participation games", mimeo, Purdue University.

Collier, K., R. McKelvey, P. Ordeshook, and K. Williams (1987): "Retrospective voting: An experimental study", Public Choice, 53, 101-130.

Croson, R.T.A., and M.B. Marks (2000), "Step returns in threshold public goods: a meta- and experimental analysis", Experimental Economics, 239-259.

Davis, D.D., en C.A. Holt (1993): "Experimental economics”, Princeton University Press, Princeton.

Davis D.D. and R.J. Reilly (1998): "Do too many cooks always spoil the stew? An experimental analysis of rent-seeking and the role of a strategic buyer", Public Choice 95, 89115.

Downs, A. (1957), "An Economic Theory of Democracy", Harper and Row, New York.

Eavey, C., and G. Miller (1984): "Fairness in majority rule games with a core", American Journal of Political Science, 28:3 (August), 570-586.

Fehr, E., and S. Gächter (2000a): "Fairness and retaliation", Journal of Economic Perspectives, 14, 159-181.

Fehr, E., and S. Gächter (2000b): "Cooperation and punishment in public goods experiments", American Economic Review, 90, 980-994. 
Fehr E., and K.M. Schmidt (1999): "A theory of fairness, competition and cooperation", Quarterly Journal of Economics, 114, 817-868.

Fiorina, M.., and Ch. Plott (1978): "Committee decisions under majority rule: An experimental study", American Political Science Review, 72, 575-598.

Goeree J. and Ch. Holt (2000): "An explanation of anomalous behavior in binary-choice games: Entry, voting, public goods, and the volunteers' dilemma", mimeo, University of Virginia.

Großer, J. and T. Kugler (2002): "The impact of group size uncertainty on voter turnout - an experiment on a 'standard' and 'modified' participation game", mimeo, University of Amsterdam.

Großer, J, W. Elberfeld, and T.Giertz (2002): "An experimental study of the polity game", mimeo, University of Amsterdam.

Großer, J. and A. Schram (2002): "The influence of neighborhood information exchange on voter turnout - an experimental study of a modified participation game", mimeo, University of Amsterdam.

Güth W., and H. Weck-Hannemann (1997): "Do people care about democracy? An experiment exploring the value of voting rights", Public Choice, 91, 27-47.

Hoffman, E., and Ch. Plott (1983): "Pre-meeting discussions and the possibility of coalitionbreaking procedures in majority rule committees", Public Choice, 421-439.

Isaac, R.M., J. Walker and S. Thomas (1984): "Divergent evidence on free riding: An experimental examination of possible explanations", Public Choice 43, 1, 113-149.

Isaac, R.M., J. Walker and A. Williams (1994): "Group size and the voluntary provision of public goods: Experimental evidence utilizing large groups", Journal of Public Economics, 54, 1-36.

Kirchsteiger, G., and A. Prat (2000): "Inefficient equilibria in lobbying", forthcoming in the Journal of Public Economics. 
Ledyard, J, (1984): "The pure theory of large two-candidate elections", Public Choice 44, 7-41.

Ledyard, J. (1995): "Public goods: a survey of experimental research", in The Handbook of Experimental Economics, by J. Kagel and A. Roth (eds.), Princeton University Press, 111194.

Kagel, J.H. and A.E. Roth (eds) (1995): "The Handbook of Experimental Economics", Princeton University Press, Princeton.

McKelvey R., en P. Ordeshook (1980): "Vote trading: An experimental study," Public Choice, 35:2 151-84.

McKelvey R. en P. Ordeshook (1990): "A decade of experimental research on spatial models of elections and committees," in Readings in the Spatial Theory of Voting, edited by J. M. Enlow and M. J. Hinich, Cambridge, England: Cambridge University Press, 99-144.

McKelvey en Ordeshook (1993): "Information and elections: retrospective voting and rational expectations", in Experimental Foundations of Political Science by D. Kinder and T. Palfrey (eds.), The University of Michigan Press, 333-362.

McKelvey R. en T. Palfrey (1998): “An experimental study of jury decisions," California Institute of Technology, Discussion Paper.

McKelvey, R. and T. Palfrey (1995): "Quantal response equilibria in normal form games", Games and Economics Behavior, 7, 6-38.

Millner, E.L. and M.D. Pratt (1989): “An experimental investigation of efficient rentseeking", Public Choice 62, 139-151.

Niskanen,W. (1971): "Bureaucracy and Representative Government", Aldine-Atherton.

Offerman, T., J. Sonnemans, and A. Schram (1996): "Value orientations, expectations, and voluntary contributions in public goods", Economic Journal 106, 817-845.

Olson, M. (1965): "The Logic of Collective Action", Harvard University Press, Cambridge. 
Olson M. and R. Morton (1994): "Entry in spatial competition and strategic uncertainty" Discussion paper Tinbergen Institute, (TI 94-123), University of Amsterdam.

Palfrey, T.R. and J.E. Prisbrey (1997): "Anomalous behavior in linear public goods experiments: how much and why?", American Economic Review, 87, 829-846.

Palfrey, T.R., and H. Rosenthal (1983): "A strategic calculus of voting", Public Choice, 41,753.

Plott, C.R. (1982): "Industrial organization theory and experimental economics", Journal of Economic Literature 20: 1485-1587.

Potters, J., de Vries, C.G., and F. van Winden (1998): "An experimental examination of rational rent-seeking", European Journal of Political Economy, 14, 783-800.

Potters, J., and F. van Winden (1992): "Lobbying and asymmetric information", Public Choice, 74, 269-292.

Riedl, Arno, and van Winden, Frans A.A.M. (2001): "Does the wage tax system cause budget deficits?", Public Choice, 109, 371-394.

Schram, A.J.H.C. (1991): "Voter Behavior in Economic Perspective"; Springer Verlag, Heidelberg.

Schram, A. (2000): "Sorting out the seeking: rents and individual motivation", Public Choice, $103,231-258$.

Schram, A., and J. Sonnemans (1996a): "Voter turnout as a participation game: an experimental investigation", International Journal of Game Theory, 25, 385-406.

Schram, A., and J. Sonnemans (1996b): "Why people vote: experimental evidence", Journal of Economic Psychology, 17, 417-442.

Smith, V.L. (1994): "Economics in the laboratory", Journal of Economic Perspectives, 8, 113-131. 
Sonnemans, J, A. Schram, and T. Offerman (1998): "Public good provision and public bad prevention: The effect of framing", Journal of Economic Behavior and Organization, 34, 143161.

Sutter, M. (1999): "Public bad prevention by majority voting on redistribution - Experimental evidence," mimeo, University of Innsbruck.

Weimann, J., C-L. Yang, and C. Vogt (2000): "An experiment on sequential rent-seeking", Journal of Economic Behavior and Organization, 41, 405-426.

Williams, K. (1991): "Candidate convergence and information costs in spatial elections: An experimental analysis", in: "Laboratory Research in Political Economy", by T. Palfrey (ed.), The University of Michigan Press, 113-135.

van Winden, F. (1999): "On the economic theory of interest groups: towards a group frame of reference in political economics", Public Choice, 100, 1-29.

Van Winden, F. (2002): "Experimental investigation of collective action", forthcoming in Political Economy and Public Finance: The Role of Political Economy in the Theory and Practice of Public Economics, by S. Winer and H. Shibate (eds.), Edward Elgar.

van Winden, F., and R. Bosman (1996): "Experimental research in public economics", in: Experiments in Economics - Experimente in der Ökonomie, Ökonomie und Gesellschaft, Jahrbuch 13, Campus Verlag, Frankfurt.

Wit J. (1997): "Dynamics and Information Aggregation in Elections and Markets", PhDthesis, University of Amsterdam. 